\title{
목동아크로빌신축공사
}

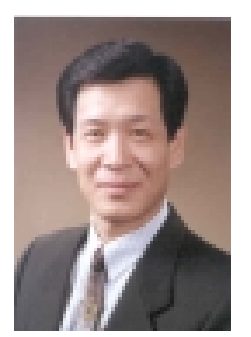

김 종 인

대림산업 부사장

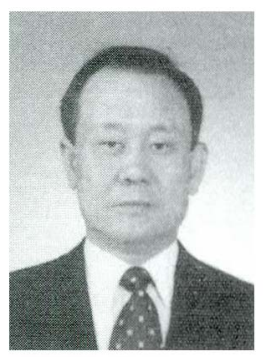

권 용 석 현장소장

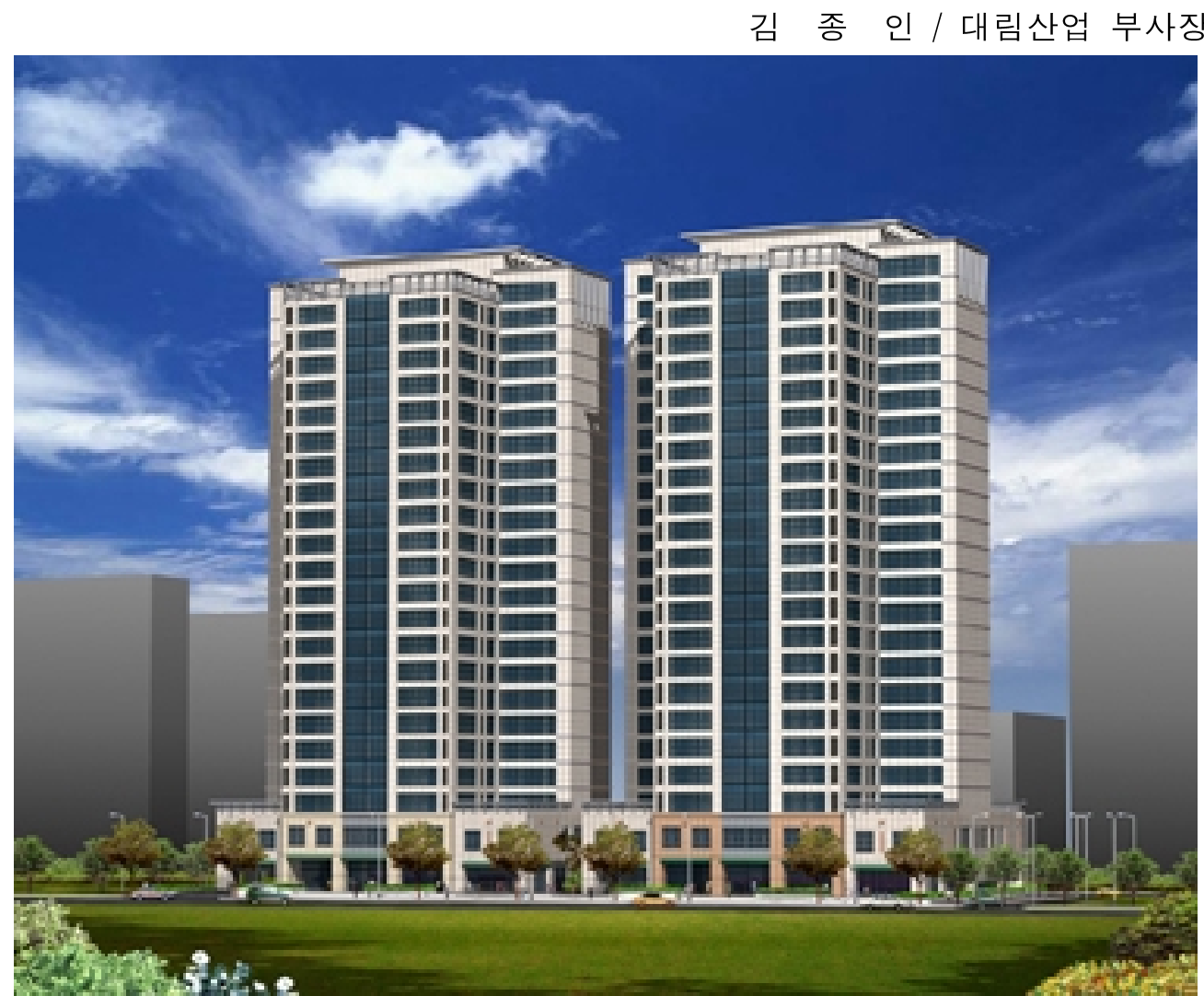

$\mathrm{N}$ 건설의 부도와 함께 공사가 중단 되었다.

이에 수분양자들이 대책위원회를 구성하여 조합을 결성하고 다시 사 업을 추진, 2000년 6월 사업지 토지 를 경락받고 이후 건설사들의 수주 경쟁을 거쳐 지난 해 1 월 대림산업 과 사업계약을 체결하고 2 월 공사를 재개하였다.

\section{2) 공사개요}

목동아크로빌 현장은 목동신시가 지 내 10 단지와 12 단지 사이의 일반 상업 지역에 위치하고 있으며, 건물 형태는 대칭형의 쌍둥이 건물로 $1^{2} 2$ 층은 $\mathrm{BOX}$ 형으로 저층부를 이루고 323 층은 십자형 평면으로 고층부 를 형성하고 있다.

외부벽체는 창호부분을 $\mathrm{AL}$ 커튼 월과 $\mathrm{AL}$ 시스템창으로 구성하고, SPANDRAL 부분과 좌우측벽은 화 강석 버너마감을 사용하여 미려하
면서도 중량감 있는 외관을 보여준 다.

현장에는 다양한 공법이 적용되 고 있는데 지하층은 ISLAND와 TOP-DOWN공법, 지상층은 코아선 행공법이 적용되었고, 철골공사와 합성 $\mathrm{DECK} \mathrm{SLAB}$ 공사가 완료되면 $\mathrm{AL} /$ 석재커튼월 공사가 진행된다.

건축공사 개요는 아래와 같다.

- 발 주 처 : 목동나산V수분양자 조합

- 설계·감리: (주)A-GROUP

- 시 공 사 : 대림산업 주식회사

- 지역지구 : 일반상업/고도제한

- 대지면적 : 5,340M2 (1,615평)

- 건축면적 : $3,190 \mathrm{M} 2$ ( 965평)

- 연 면 적 : 74,426M2 (22,514평)

- 규 모 : 지하6층 지상 23 층

$$
2 \text { 개동 }
$$

- 구 조 : S.R.C조

- 공사기간 : 24 개월

(2001.02.26 2003.02.25) 


\section{- 층별용도}

지상 323 층 : 공동주택 244세대 지상 2 층 : 오피스텔 52 세대

지상 1 지하1층 : 근생시설

지하 2 5층 : 주차장

지하 6 층 : 기계/전기실

\section{2. 현장조직}

현장조직은 권용석 소장과 건축 직 6 명, 설비직 2 명, 전기직 1 명, 관 리직 2 명으로 총 12 명의 직원으로 구성되어 있으며 안전, 품질, 공정 및 공사관리를 수행하고 있다.

\section{3. 공사진행현황}

착공 전 현장은 지하연속벽공사 와 기둥공사 $(\mathrm{RCD}) 72$ 개소 중 64 개 소, 코아부분 훍막이 가시설과 터파 기 공사를 완료한 상태였으나, 기시 공사의 부도과정에서 품질관리에 헛점이 생기고 수년간 관리되지 못 한 채 방치된 현장에는 착공 초기부 터 많은 문제점이 있었다.

선시공된 코아주변 토류벽의 STRUT는 지하층 SLAB LEVEL과 충돌되어 공사 진행을 곤란하게 하 였고, 수직도 관리가 미흡했던 $\mathrm{RCD}$ COLUMN은 TEMPORARY $\mathrm{BEAM}$ 을 사용한 수직도 바로잡기 공사로 인해 많은 비용이 소요되었 으며 공기는 지연되었다.

이는 그동안의 공백기간을 조금 이나마 만회해 보고자 최소한으로 계획된 전체 24 개월의 공사기간을 준수하는 데에도 상당한 부담으로 작용되었고 다양한 공기만회대책을 수립하는 노력으로 이어졌다.

공정진행현황을 보면 착공 이후 잔여 $\mathrm{RCD}$ 기둥공사와 지하층 코아 골조공사에 5 개월 가량이 소요되었 고 이후 지상층 골조공사는 8 개월여 만인 올해 3 월에, 지하층 골조공사 는 6 월초에 완료될 예정이다.

$\mathrm{TOP}-\mathrm{DOWN}$ 공사에서 지하층골
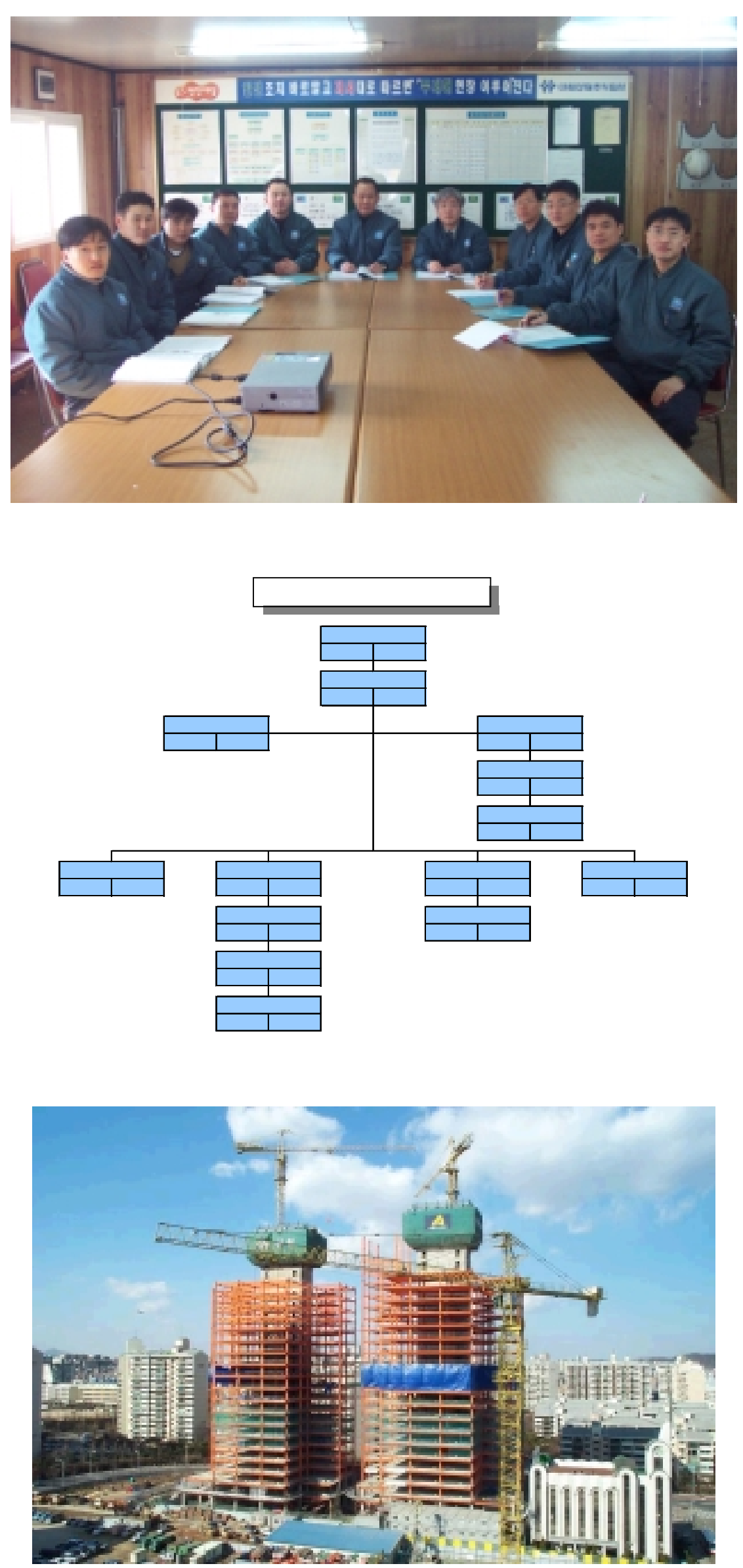
조공사가 주공정을 벗어나 지상층 골조공사보다 늦게 완료되는 것은 사업추진 과정에서 발생한 설계변 경에 따른 현장의 특수성에 따른 것 인 데 이는 $\mathrm{RC}$ 구조 였던 지상층골 조가 $\mathrm{SRC}$ 로 변경되면서 지하층 기 둥이 부담해야 할 하중이 훨씬 줄어 들었기 때문이다.

골조공사가 마무리되어 가면서 외부 커튼월공사가 본격적으로 착 수되었고 내부마감공사를 위한 경 량벽체공사가 준비되고 있다.

\section{4. 원가절감 및 공기단축사 례}

\section{가. 코아 SLAB 연장시공}

1) 지하층 골조공사 방법

두 개의 코아부분을 선굴착하여 MAT기초로부터 지상까지 코아구 조물을 선구축한 후 지하연속벽과 코아 구조물을 연결하여 슬라브를 시공하는 ISLAND 공법과 TOP$\mathrm{DOWN}$ 공법을 같이 사용하여 지하 층 골조공사가 이루지도록 설계되 어 있다.

\section{2) 지하층 코아골조 시공방법}

선굴착을 위해 설치된 코아주변 훍막이 가시설 내부에 기초와 최하 층(BF6)구조물을 시공하고, 충분히 양생한 후 코아구조물과 훍막이 사 이를 되메우기하여 훍막이 배면 토 압을 코아구조물에 전이시킨 후 상 부의 STRUT를 해체하면서 상층부 $\left(\mathrm{B} 5{ }^{\circ} \mathrm{B} 1\right)$ 로 골조공사를 진행한다.

\section{3) 문 제 점}

공사 착수 전 설계도서검토 과정 에서 $\mathrm{CORE}$ 옹벽의 내력확인을 위 한 구조 검토 결과, $\mathrm{CORE}$ 벽체가 훍막이 배면의 토압을 견딜 수 없는 구조임이 판명되어 당초 시공절차 대로 되메우기 및 STRUT를 해체 하는 공법을 적용할 수 없었다.

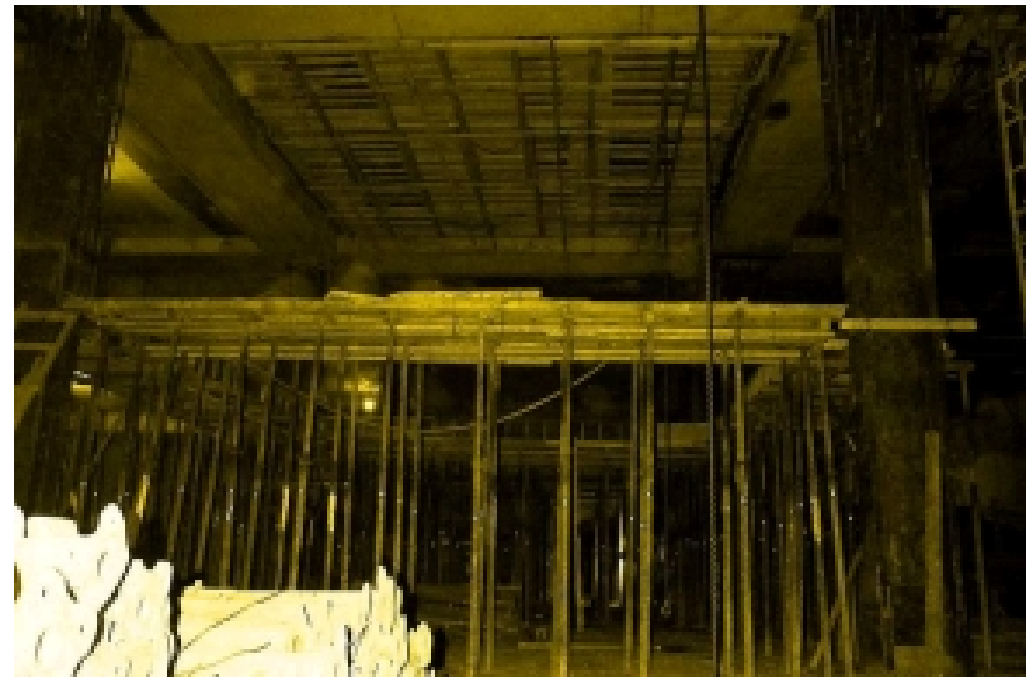

\begin{tabular}{|c|c|c|c|c|c|c|c|c|c|c|c|c|c|c|c|c|}
\hline & & & & & & & & & & & & & & & & \\
\hline & & & & & & & & & & & & & & & & \\
\hline 양생 & 7 & & & & & & & & & & & & & & & \\
\hline 해체 & 5 & & & & & & & & & & & & & & & \\
\hline 굴토 & 9 & & & & & & & & & & & & & & & \\
\hline 버림 Con'c & 1 & & & & & & & & & & & & & & & \\
\hline 먹메김 & 1 & & & & & & & & & & & & & & & \\
\hline 자재반입 & 4 & & & & & & & & & & & & & & & \\
\hline $\mathrm{RCD}$ 기둥청소 & 5 & & & & & & & & & & & & & & & \\
\hline 거푸집 & 10 & & & & & & & & & & & & & & & \\
\hline 커플러용접/압접 & 8 & & & & & & & & & & & & & & & \\
\hline 철근조립 & 7 & & & & & & & & & & & & & & & \\
\hline 전기/설비 & 3 & & & & & & & & & & & & & & & \\
\hline 검측 & 1 & & & & & & & & & & & & & & & \\
\hline 타설 & 1 & & & & & & & & & & & & & & & \\
\hline
\end{tabular}

\begin{tabular}{|c|c|c|c|c|c|c|c|c|c|c|c|c|c|c|c|c|c|}
\hline 작 업 명 & Du & & \begin{tabular}{l|l}
4 & 6 \\
\end{tabular} & \begin{tabular}{l|l}
6 & 8 \\
\end{tabular} & 10 & \begin{tabular}{l|l}
12 & 1 \\
\end{tabular} & \begin{tabular}{|l|l|}
4 & 16 \\
\end{tabular} & \begin{tabular}{|l|l|}
18 & $2 C$ \\
\end{tabular} & 22 & 242 & & 30 & \begin{tabular}{l|l}
32 & 3 \\
\end{tabular} & \begin{tabular}{l|l}
34 & 36 \\
\end{tabular} & 38 & & \begin{tabular}{l|l|}
42 & 44 \\
\end{tabular} \\
\hline 양생 & 7 & & & & & & & & & & & & & & & & \\
\hline 해체 & 3 & & & & & & & & & & & & & & & & \\
\hline 굴토 & 9 & & & & & & & & & & & & & & & & \\
\hline 버림 Con'c & 1 & & & & & & & & & & & & & & & & \\
\hline 먹메김 & 1 & & & & & & & & & & & & & & & & \\
\hline 자재반입 & 2 & & & & & & & & & & & & & & & & \\
\hline $\mathrm{RCD}$ 기둥청소 & 5 & & & & & & & & & & & & & & & & \\
\hline 거푸집 & 6 & & & & & & & & & & & & & & & & \\
\hline 커플러용접/압접 & 6 & & & & & & & & & & & & & & & & \\
\hline 철근조립 & 6 & & & & & & & & & & & & & & & & \\
\hline 전기/설비 & 3 & & & & & & & & & & & & & & & & \\
\hline 검측 & 1 & & & & & & & & & & & & & & & & \\
\hline 타설 & 1 & & & & & & & & & & & & & & & & \\
\hline
\end{tabular}

\section{4) 대안공법}

코아구조물이 흙막이 배면토압을 견딜수 있는 방안으로 코아내부를 모두 되메우기하거나, JACKSUPPORT를 수평으로 설치하는 방
법, 타설된 $\mathrm{CORE}$ 해당층 상부 $\mathrm{SLAB}$ 에 별도의 STRUT를 설치하 는 방법 등을 검토하였으나 최종적 으로 $\mathrm{CORE}$ 벽체와 훍막이 벽체 사 이를 $\mathrm{CORE}$ 와 연결되는 지하주차장 
$\mathrm{SLAB}$ 를 먼저 연장시공하여 영구구 조물로써 토류벽을 지지하는 방법 을 채택하였다.

\section{5) 공법변경에 따른 정량적성과}

되메우기 공법 시 층당 20 일의 공 기가 예상되었으나 슬라브 연장시 공의 경우에는 층당 15 일이 소요되 어 층당 5 일, 6 개층 모두 30 일의 공 기 단축효과가 나타났으며, $9800 \mathrm{M} 3$ 에 해당하는 토사반입과 되메우기, 이후 TOP-DOWN 토공사 중 굴토 및 상차, 잔토처리에 소요되는 비용 으로 약 8천만원의 공사원가 절감효 과가 있었다.

\section{나. HANGING FORM 공법} 1) 지하층 SLAB FORM 설치방법 TOP-DOWN 공법 중 지하층 $\mathrm{SLAB} F \mathrm{FORM}$ 시공방법으로 SUPPORT 지지방식과 NONSUPPORT 방식을 혼용한 HANGING FORM공법을 적용하고 있다.

2) SUPPORT 지지방식의 문제점 하부층의 골조공사를 진행하기 위한 지하층 터파기 시 상부층의 공 사용자재를 신속히 해체,정리하여야 하나 막대한 양의 가설자재를 정리 하고 반출하는 데는 많은 비용과 시 간이 소요되며, 반출자재의 적재공 간을 마련하는 것도 용이하지 않다.

\section{3) 현장적용공법}

상부층의 $\mathrm{CON}^{\prime} \mathrm{C}$ 가 양생되어 기 준강도를 발현하면 거푸집은 그대 로 존치한 체 SUPPORT만을 해체, 반출하고 하부층 터파기 공정를 시 행한다.

터파기가 완료되면 상부 $\mathrm{FORM}$ 을 보와 SLAB 순서로 CHAIN을 이용 하여 탈형하고 달아내려서 (HANGING) 재반입 된 SUPPORT 로 지지한다.

4) 공기단축효과
SUPPORT방식으로는 층당 계획 공기 44 일로도 지하 1 개층 골조공사 를 완료할 수 없었으나 HANGING FORM 공법 적용 시에는 거푸집을 해체,정리하는 시간과 하부층 시공 을 위해 거푸집을 다시 반입하는 시 간, 그리고 거푸을 시공하는 시간까 지 줄일 수 있어 1 개층 당 9 일 이상 의 공기단축효과를 가져왔다.

\section{다. 지상층 SLAB골조공사 공기 단축}

1) 지상층 골조공사 방법

우리현장은 코아선행공법에 따라 코아 골조공사가 선행되고, 주변의 철골시공 후 구조용 $\mathrm{DECK}$ 로 $\mathrm{SLAB}$ 를 형성하는 공법이나, 코아 주변의 $\mathrm{SLAB}$ 는 합판거푸집공법으 로 설계되어있어 $\mathrm{SRC}$ 조와 코아선 행공법의 공기단축효과가 반감되는 상황이다.

\section{2) 설계상의 문제점}

SUPPORT가 불필요한 DECK $\mathrm{SLAB}$ 구간은 신속한 작업이 이루 어지고 무지보공임으로 복층시공까 지 가능하지만 합판거푸집 적용구 간은 SUPPORT 시공이후 거푸집과 철근배근, 설비·전기 등 후속공정 에 많은 시간이 소요되므로 코아골 조와 철골공사 시공속도에 비해 지 상층 $\mathrm{SLAB}$ 골조공사의 공기가 상당 히 지연되고 있는 실정이다.

\section{3) 대처방안}

$\mathrm{SLAB}$ 골조공사가 진행중 인 층 보다 5 6개층 상부층에 합판거푸집 시공구간을 $\mathrm{DECK}$ 시공이 가능한 구조가 되도록 철골을 보강시공하 여 중간층을 형성한 후 상,하층 동시 에 $\mathrm{SLAB}$ 골조공사가 가능하도록 하고 있다.

\section{5. 무재해 준공}

위에서 소개한 사례외에도 공기 단축을 위한 현장의 노력은 각별하
며, 어떤 직원도 자신있는 말을 아낄 정도로 공정관리에 온 힘을 다하고 있다.

그럼에도 불구하고 현장에서 가 장 최선을 다하고 있고, 중요한 현장 관리 목표는 안전이며, 무재해 준공 이다.

무재해준공이야 말로 그 무엇보 다도 값진 성과이며, 가장 큰 바람이 라는 것이 전 직원의 한결같은 생각 이다.

내년 2월이면 전 직원과 현장근로 자의 땀의 결실이며, 6 년여에 걸친 조합원들의 꿈을 담은 작품인 목동 아크로빌이 우리들 앞에 우뚝 설 것 이다. 